\title{
Um estudo de caso sobre o Turismo Cultural em Porto Nacional, Tocantins (Brasil)
}

\section{A case study on Cultural Tourism in Porto Nacional, Tocantins (Brazil)}

\author{
Núbia Nogueira do Nascimento (NASCIMENTO, N. N. do) ${ }^{*}$ e \\ Ordália Dias da Silva Guilherme (GUILHERME, O. D. da S.)
}

RESUMO - Nesse estudo se propõe discutir as ações que embasam a prática e a existência do Turismo Cultural na cidade de Porto Nacional no estado do Tocantins (Brasil). Discute-se a prática do desenvolvimento do turismo cultural urbano com o fim de facilitar a promoção das atividades turísticas na cidade. A metodologia consistiu na aplicação de um questionário ${ }^{1}$ aos turistas que visitaram a Catedral Nossa Senhora das Mercês e o Museu Histórico e Cultural no período referente ao mês de julho e dezembro de 2013, com objetivo de conhecer o símbolo mais representativo considerado ponto turístico e/ou histórico para os turistas. Ao segundo grupo, os moradores do centro histórico da cidade de Porto Nacional, Tocantins, em especifico, a área tombada, foram feitas entrevistas ${ }^{2}$. Para esse grupo, foram realizadas entrevistas a respeito da participação dos moradores no processo de patrimonialização do Centro Histórico da cidade de Porto Nacional-TO e a opinião sobre a prática do turismo cultural na cidade. No decorrer da análise chegou-se conclusão do ponto de vista dos turistas quanto a existência do turismo cultural na cidade e o ponto de vista dos moradores quanto a participação do processo de tombamento e a existência do turismo cultural.

Palavras-chave: Turismo; Turismo Cultural; Tombamento; Patrimonialização; Porto Nacional/TO.

ABSTRACT - This study aims to discuss the actions that support the practice and the existence of Cultural Tourism in Porto Nacional, a city in the state of Tocantins, Brazil. It discusses the development practice of urban cultural tourism in order to facilitate the promotion of tourist activities in the city. The methodology consisted in the application

\footnotetext{
*Formação: Graduação em Biblioteconomia pela Universidade Federal de Goiás (UFG), Especialização em MBA em Gestão Empresarial pela Universidade Federal do Tocantins (UFT). Mestrado em Geografia pela Universidade Federal do Tocantins (UFT). Atividade profissional: Bibliotecária - Documentalista da Universidade Federal do Tocantins - Campus Porto Nacional - TO. Endereço físico para correspondência: Rua Maria Lopes, 510. Bairro: Jardim Brasília. CEP: 77500-000 - Porto Nacional/TO Brasil. E-mail: nascimento.nubia@hotmail.com

*** Formação: Graduação em Geografia pela Fundação Universidade Federal do Tocantins; Especialização em Metodologia do Ensino da História e Geografia e em Gestão, Orientação e Supervisão Escolar pela Faculdade Suldamérica; Mestrado em Geografia pela Universidade Federal do Tocantins (UFT). Mestrado em Ciências da Educação - Universidad del Norte - UNINORTE-PY. Atividade profissional: Professora no Instituto Federal de Educação, Ciência e Tecnologia do Tocantins (IFTO) - Campus de Porto Nacional. É membro do grupo de pesquisa da OPTE - Observatório de Políticas Territoriais e Educacionais na UFT e do grupo Multidisciplinar em Trabalho colaborativo - GPMTC no IFTO. Endereço físico para correspondência: Avenida Goiás, 410. Bairro: Jardim Querido. CEP: 77500-000 Porto Nacional/TO - Brasil. E-mail: ordaliaguilherme@ hotmail.com

${ }^{1}$ Disponível no final do artigo, em apêndice A.

${ }^{2}$ Disponível no final do artigo, em apêndice B.
} 
of a questionnaire to the tourists who visited the Nossa Senhora das Mercês Cathedral and the Historical and Cultural Museum in the period of July and December 2013, in order to know the most representative symbol considered tourist point and/or Historic for tourists. To the second group, the residents of the historic center in Porto Nacional were interviewed, specifically, those from the heritage-listed area. These interviews were about the participation of the residents in the patrimonialization process of the Historic Center of Porto Nacional, and what their opinion on the cultural tourism practice in this city. During the analysis, a conclusion was reached about the tourists' opinion regarding the existence of cultural tourism in the city as well as the residents' point of view concerning their participation in the heritage process, and the existence of cultural tourism.

Key words: Tourism; Cultural Tourism; Heritage Process; Patrimonialising; Porto Nacional/TO. 


\section{INTRODUÇÃO}

Porto Nacional é uma cidade do interior do estado do Tocantins que teve seu centro histórico tombado pelo Instituto do Patrimônio Histórico e Artístico Nacional (IPHAN) no ano de 2008. Para Oliveira (2010), é uma cidade histórica e representativa por valores e traços culturais, uma das cidades mais antigas do Estado, aproximadamente do século XVII. Ainda, Oliveira (2010) a considera representativa, pois em meados de 1910, houve vários acontecimentos: a difusão da medicina com a influência do médico Francisco Aires da Silva e a evolução do ensino, com a chegada das freiras dominicanas direto da França, elas intensificaram a educação e a religião na cidade como o "Catolicismo".

Nesse sentido, esse artigo tem como proposta discutir sobre o Turismo Cultural na cidade, bem como verificar se houve a participação dos moradores para o tombamento do seu centro histórico. O trabalho foi fruto de uma das etapas da pesquisa realizada no mestrado em Geografia da Universidade Federal do Tocantins (UFT)

O trabalho está estruturado primeiramente em uma análise conceitual sobre turismo cultural e o que vem a ser atividade turística, em seguida a verificação dos dados obtidos a partir dos turistas, sobre informações e atrativos turísticos que a cidade de Porto Nacional estava oferecendo, e, por fim, o desfecho sobre a ação do turismo na cidade por meio da análise da opinião dos moradores.

\section{DEFINIÇÃO CONCEITUAL DO TURISMO CULTURAL}

Segundo Barretto (1992, p. 35):

[...] há um consenso de que a abrangência social do turismo é irredutível a uma só categoria. A sua peculiaridade reside, justamente, em abranger aspectos econômicos, psicológicos, sociológicos e técnicos; é um fenômeno polifacético que só pode ser estudado com um processo de interação social.

Conforme a conceituação de Brasil (2006, p. 35) Turismo Cultural compreende as "atividades turísticas relacionadas à vivência do conjunto de elementos significativos 
do patrimônio histórico e cultural e dos eventos culturais, valorizando e promovendo os bens materiais e imateriais da cultura". Também se tem que:

O turismo cultural, em cidades históricas, pode ser um meio para revalorizar, afirmar ou recuperar os elementos culturais e históricos que caracterizam e identificam cada sociedade perante um mundo globalizado. $\mathrm{O}$ turismo cultural também pode contribuir para gerar uma tomada de consciência em relação à preservação do patrimônio, tanto tangível como intangível de uma cidade ou vila histórica (MARUJO; SERRA; BORGES, 2013, p. 8).

O Turismo Cultural possui inúmeras possibilidades de construção de produtos turístico-culturais sustentáveis por meio da valorização do patrimônio cultural nacional, atendendo, com isso, aos novos consumidores, que estão cada vez mais interessados em ampliar os conhecimentos sobre a cultura de determinado local e que valorizam cada vez mais as experiências autênticas (BRASIL, 2010, p. 31). O Turismo Cultural:

[...] tem a finalidade de conhecer a geografia histórica, os monumentos, as obras e outros bens culturais que a cidade oferece, mas também tem o objetivo crucial de desfrutar dos recursos e das atratividades oferecidos pela localidade. Todos eles, direta ou indiretamente, contribuem para o reconhecimento do valor patrimonial da cidade no todo (NASCIMENTO, 2014, p. 17).

Nesse sentido, é preciso que o profissional do Turismo Cultural tenha uma boa leitura sobre os atrativos culturais explorados: busque novos desafios, tenha conhecimento da região, capacidade de realizar interpretações sobre o bem apresentado e sua relação com a história, tenha boa comunicação, iniciativa e empatia com o visitante, excursionista e/ou turista, transmita interesse e motivação para o grupo e manifeste um profundo conhecimento e respeito à cultura local (MOLETTA, 2001).

Ou seja, Nascimento (2014, p. 30-31) conceitua que: "para conhecer a história local, é preciso primeiramente fazer uma pesquisa exploratória nos arquivos, centros de informação e/ou unidades de informações, os quais possam fornecer documentos que comprovem a memória local”. Nesse mesmo sentido, García Canclini (1997, p. 37) afirma que:

[...] o histórico-territorial, ou seja, o conjunto de saberes, costumes e experiências, organizado ao longo de várias épocas, tem relação com territórios étnicos, regionais e nacionais, e que se manifesta, sobretudo, no patrimônio histórico e na cultura popular tradicional. 
Seguindo essa linha de raciocínio, Costa (2014, p. 35) cita que: "o direcionamento do atual interesse para o turismo cultural está calcado em sua crescente popularidade como fonte de atração de visitantes, supostamente donos de um perfil procurado por todo o trade turístico [...]". Costa (2014, p. 39) afirma ainda que um conceito mais completo de turismo cultural deve ser construído considerando-se também uma análise mais ampla das motivações de seus participantes, das características de seu objeto e de seu público, da interatividade ou vivência de experiências culturais e das possíveis relações com a preservação e a educação por meio do patrimônio cultural.

De acordo com Barretto (1992), Turismo Cultural seria aquele que não tem como atrativo principal um recurso natural. No entanto, seria aquele que tem como objetivo conhecer os bens materiais e imateriais produzidos pelo homem. Conforme Costa (2014), o turista cultural, genericamente, é aquele que consome o produto turístico cultural. Suas particularidades têm sido traçadas de forma ampla, levando à suposição de um perfil bastante definido para esse tipo de turista, "quando comparado com o público em geral, ele revela possuir maior poder aquisitivo [...]. Os "turistas culturais específicos" vivem em áreas centrais das principais cidades, próximos de ampla gama de facilidades culturais" (COSTA, 2014, p. 55).

\section{ASPECTOS METODOLÓGICOS}

No estudo se propôs verificar, a possibilidade de o turismo cultural se tornar facilitador da promoção de atividades turísticas da cidade, uma vez que o reconhecimento da cultura local poderia promover a preservação e valorização da cidade por meio dos bens materiais e/ou imateriais. Propõem-se ainda, nesse estudo a discussão e a reflexão sobre o processo patrimonial na cidade de Porto Nacional.

No primeiro momento, houve a aplicação de questionários para os turistas que haviam visitado a Catedral e o Museu no período de férias referente a dois períodos: julho e dezembro de 2013. A escolha desse período foi justamente por ser período de férias escolares no estado, de ocorrência de festas tradicionais como a Semana da 
Cultura e a abertura da Praia Porto Real, que margeia a cidade, assim havendo um grande fluxo de turistas e/ou excursionistas na cidade.

Os questionários foram aplicados aos turistas, como primeira etapa da pesquisa. Porto Nacional, considerada pelo Instituto de Patrimônio Histórico e Artístico Nacional (IPHAN, 2013), berço cultural do patrimônio histórico do estado, leva a pensar as práticas existentes em termos e/ou conceitos sobre cultura e tradição. Com base em uma das questões contidas no questionário, surgiu a reflexão para o questionamento se existia o turismo cultural na cidade e se os bens representavam a tradição ou se seriam apenas o costume que permeava a população portuense, pois a gênese da cidade foi articulada nos três acontecimentos em meados de 1910, afirmados por Oliveira (2010): a chegada de um médico à cidade de Porto Nacional, o surgimento da imprensa com jornais impressos e a ascensão da educação ligada à religião. Assim, considerou-se poder questionar se a cultura permaneceu na gênese e se ainda estava presente na vida dos portuenses ou seria apenas tradição.

No segundo momento, foram feitas entrevistas com os moradores da poligonal de tombamento (área tombada) com objetivo de obter informações sobre a participação dos moradores quanto ao processo de tombamento.

Para realizar a pesquisa, estabeleceu-se como espaço de referência a "Poligonal de tombamento", , que consiste em uma delimitação no perímetro urbano, baseada em vários critérios, como em arquitetura, construções, períodos históricos entre outras atribuições. Essa delimitação foi realizada pelo IPHAN no ano de 2008 na área de proteção tombada do Patrimônio Histórico de Porto Nacional. No ano de 2011, houve uma retificação, uma ampliação dessa área tombada (ver FIGURA 1), por meio da publicação em Diário Oficial da União (D.O.U.), em 2012. O contorno vermelho na (FIGURA 1), refere-se à área ampliada no Centro Histórico de Porto Nacional/TO.

\footnotetext{
${ }^{3}$ O poligonal de tombamento é a área delimitada pelo IPHAN em 2008 e retificada no ano de 2012, e representa hoje a área tombada na cidade de Porto Nacional/TO.
} 
FIGURA 1 - POLIGONAL DE TOMBAMENTO DE PORTO NACIONAL/TO - 2012

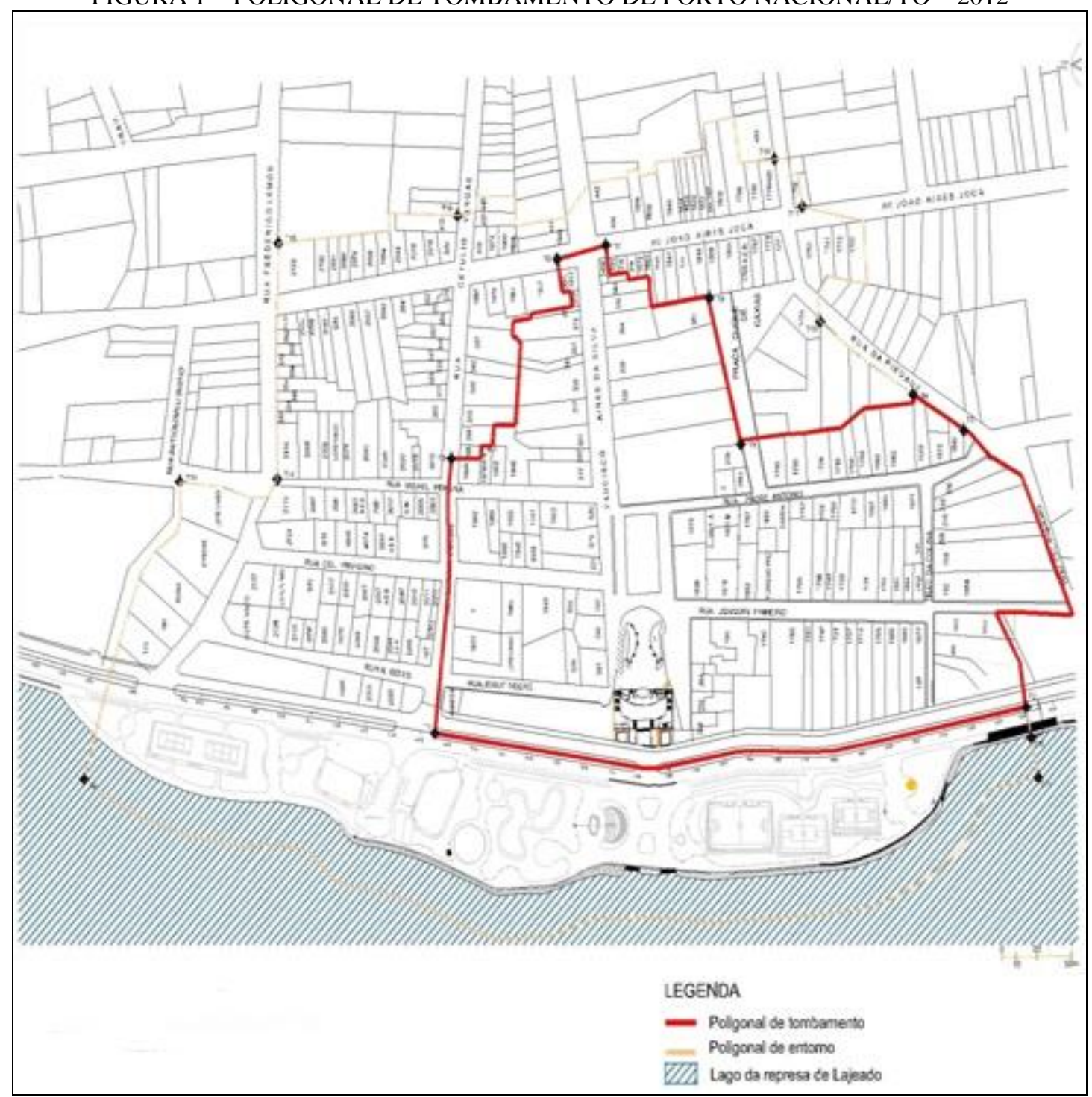

FONTE: IPHAN, 2012.

De acordo com o IPHAN (2013), a partir do ano de 2012, passa a ser válida a nova área tombada, assim, houve um aumento na área e na quantidade de imóveis tombados. Para a presente pesquisa foram visitados exatamente cento e quatro imóveis, mas apenas setenta e duas pessoas foram entrevistadas, o restante das pessoas estava com imóvel à venda, não quiseram participar ou não foram encontradas em sua residência. Houve três tentativas para aqueles residentes que não foram encontrados na primeira tentativa, respectivamente: em horário comercial, horário de almoço entre $12 \mathrm{~h}$ às $14 \mathrm{~h}$ e/ou após as $18 \mathrm{~h}$ e, por fim, nos finais de semana sábado e/ou domingo.

A pesquisa empírica foi realizada com aplicação de questionários semiestruturados a cinquenta e cinco turistas e entrevistas de caráter também 
semiestruturado, com os setenta e dois moradores do centro histórico de Porto Nacional/TO.

Para Lakatos e Marconi (1999), na entrevista semiestruturada, normalmente as perguntas são abertas e o entrevistador prossegue com a entrevista de forma natural e com diálogos informais, para maior aproximação com o entrevistado. Observando-se as expressões faciais e gestos corporais, também se pode fazer uma interpretação, destacando, assim, a pesquisa de cunho qualitativo e quantitativo. Dessa forma, Minayo (2007) afirma que, na pesquisa quantitativa, os resultados são obtidos por meio dos números. Nesse sentido, quantifica a pesquisa por meio da estatística, enquanto a qualitativa tem o propósito de responder questões individuais.

\section{ANÁLISE DOS DADOS}

Conforme Beni (2003, p. 38): “os recursos turísticos podem ser: materiais, imóveis, de consumo e de capital'". Dessa forma, se pode fazer uma relação com os bens “casarios" localizados no polígono de tombamento da cidade de Porto Nacional/TO. Por exemplo, a Catedral Nossa Senhora das Mercês pode ser considerada um bem material, imóvel, de consumo e de capital.

De acordo com Nascimento (2014), as cidades históricas, em específico as que possuem espaços configurados como centros históricos, antecedem ao ano de 1960 e possuem uma arquitetura com características do estilo colonial.

Nascimento (2016), afirma ainda que, pós os anos 60, as cidades passaram por processos de transformação, industrialização e urbanização crescente, havendo uma transformação constante na alteração dos seus espaços arquitetônico e urbano.

Nesse contexto, Oliveira (2010), afirma que o município de Porto Nacional acabou perdendo o espaço do transporte fluvial em função da construção da rodovia Belém-Brasília - BR 153, que foi construída em meados da década de 60 , e com o transporte rodoviário, aumentou muito o fluxo de pessoas e mercadorias às cidades interioranas do Tocantins, pois antes o acesso era muito difícil devido ao transporte fluvial ser inacessível para a maioria da população. Desse modo, a cidade de Porto Nacional que antes era um importante centro urbano vai perdendo espaço para outros 
novos centros urbanos e consequentemente a sua valorização patrimonial também passa a carecer de uma atenção especial para não perder a sua importância cultural.

\subsection{INTERPRETAÇÕES DOS TURISTAS}

Carvalho (2010, p. 52) afirma que "no âmbito do mercado de consumo turístico, as áreas urbanas e seus elementos constituintes transformam-se em espaços de interação entre a comunidade local e grupos de visitantes".

A pesquisa com os turistas contou com o trabalho exploratório e levantamento de dados por meio da aplicação de questionários destinados aos turistas e/ou excursionistas que visitaram a cidade de Porto Nacional no mês de julho e dezembro de 2013. Nos questionários aplicados se buscou obter algumas informações, como as mais evidentes, assim destacadas: a existência de turismo cultural em Porto Nacional e o monumento mais representativo da cidade. Esse período foi determinado estrategicamente devido ao maior índice de pessoas na cidade no período de férias: no mês de julho, em função da Praia Porto Real; e em dezembro, por ser um mês festivo e com comemorações com propósito de reunir familiares.

Desta maneira, posteriormente foram feitas análises quantitativas/qualitativas, interpretação e quantificação dos dados colhidos com os questionários aplicados aos turistas.

$\mathrm{Na}$ pesquisa, participaram um total de cinquenta e cinco turistas e/ou excursionistas. Foram aplicados questionários durante o mês de julho e de dezembro de 2013 em dois lugares da cidade: a Catedral Nossa Senhora das Mercês e o Museu Histórico e Cultural ${ }^{4}$.

TABELA 1 - EXCURSIONISTA E/OU TURISTA E SUA LOCALIDADE DE ORIGEM

\begin{tabular}{|c|c|}
\hline LOCALIDADE & TOTAL DE EXCURSIONISTA E/OU TURISTA \\
\hline$\overline{\mathrm{DF}}$ & 4 \\
\hline GO & 14 \\
\hline TO & 23 \\
\hline Outros & 14 \\
\hline Total geral & 55 \\
\hline
\end{tabular}

FONTE: Pesquisa de campo (2013).

* O item "outros" representa diferentes estados.

${ }^{4}$ Questionário disponível em apêndice A. 
Na (FIGURA 2), se pode verificar uma representação contida em uma das perguntas feitas no questionário, sobre qual o símbolo e/ou monumento que tinham maior representatividade histórica e cultural de Porto Nacional.

FIGURA 2 - REPRESENTAÇÃO DOS MONUMENTOS EM PORTO NACIONAL-TO

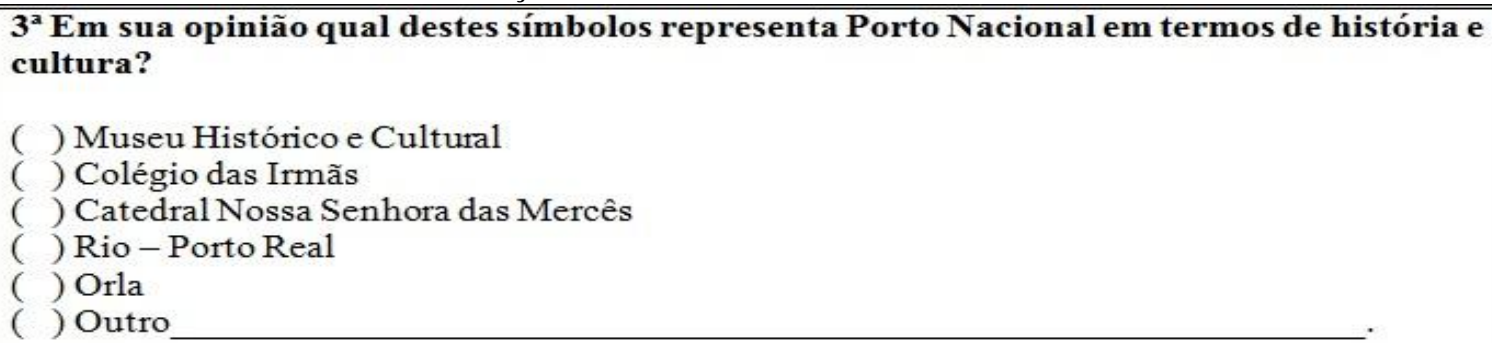

FONTE: Nascimento (2014).

Da totalidade dos turistas e/ou excursionistas que participaram da pesquisa, destacou-se o local de origem. Vinte e três dos participantes eram tocantinenses, quatorze do estado de Goiás, quatro do Distrito Federal e, por fim, quatorze pessoas eram pessoas oriundas de outros estados, como Rio de Janeiro, São Paulo, Rio Grande do Sul entre outros.

Na tabela 2, se podem verificar, em dados numéricos, as respostas que obtiveram um maior índice sobre o monumento que representava Porto Nacional na visão dos turistas referentes aos períodos de julho e dezembro.

Assim, se teve como verificar quais os símbolos que foram mais citados como monumentos que representavam Porto Nacional na visão dos turistas e/ou excursionistas.

TABELA 2 - DADOS NUMÉRICOS: QUESTIONÁRIO APLICADO AOS TURISTAS

\begin{tabular}{lc}
\hline \multicolumn{1}{c}{ BEM CULTURAL } & DADOS* \\
\hline Catedral Nossa Senhora das Mercês & 24 \\
Museu Histórico e Cultural & 18 \\
Rio Porto Real & 5 \\
Colégio das Irmãs & 3 \\
Beira Rio - Orla & 3 \\
Outros** & 2 \\
\hline
\end{tabular}

FONTE: Pesquisa de campo (2013).

* O item "outros" representa diferentes bens culturais existentes "monumentos" no centro histórico e que não foram mencionados na pergunta três do questionário.

Conforme a tabela 2 se pôde observar que o maior índice de frequência de visitação foi à Catedral Nossa Senhora das Mercês e ao Museu Histórico e Cultural de 
pessoas oriundas do estado do Tocantins. Observação que apontou certa indagação, pois, no primeiro período, em julho de 2013, dos questionários aplicados na Catedral, poucos turistas e/ou excursionistas residiam no Tocantins e a maioria em outros estados, incluindo Goiás e Distrito Federal, dados obtidos pelo questionário aplicado. Aqui se pôde observar que, por mais que tenha havido a separação territorial em 1988 entre Goiás e Tocantins, ainda havia uma aproximação muito grande entre os dois estados.

Ou seja, para aquele momento, no mês de julho, os tocantinenses eram as pessoas em minoria e que mais desconheciam sobre sua própria região. Assim, se pôde notar que a maioria dos turistas que visitaram os bens culturais de Porto Nacional/TO, no período de julho de 2013, eram pessoas oriundas de outros estados.

Quanto à área de atuação, participaram da pesquisa estudantes, professores entre outras profissões. Considerou-se ser interessante observar que os estudantes e professores somaram vinte e duas pessoas e esses destacaram o museu como referência para a preservação da história e memória, enquanto desse mesmo grupo, apenas onze entrevistados consideraram a catedral e apenas uma pessoa considerava que a Orla Beira Rio fosse a referência para preservação da história e memória. Isso aconteceu em virtude do processo de modificação espacial do cenário em que a Orla Beira Rio se encontrava, pois, foi preciso demolir muitas casas ou mesmo terrenos, considerados chácaras. Esse processo indiretamente gerou um desgosto para as pessoas que residiam às margens do rio Tocantins, pois tiveram que mudar de um local em que havia toda uma história de vida, para outro bairro desconhecido.

Quanto ao lago Porto Real, não houve nenhuma menção e pôde-se observar aqui uma mudança de valores e significados na nova geração. $O$ rio, fonte principal da cidade, enquanto sua gênese estava perdendo o valor simbólico que antes representava para os moradores e para os turistas.

Com relação aos períodos referentes ao mês de julho e dezembro, pode-se observar no gráfico 1 que vinte e seis turistas e/ou excursionistas tocantinenses, no mês de julho, descreveram o Museu como um espaço reprodutor da história e da memória da cidade. Já a Catedral obteve um maior índice, com vinte e oito turistas, que consideraram a Catedral como representação da história e memória e também como um ponto turístico. 
Quanto ao ponto turístico, notou-se que apenas dezoito turistas e/ou excursionistas dos estados de Goiás e Distrito Federal consideraram o museu como um ponto turístico. Desse mesmo grupo, vinte e duas pessoas descreveram a Catedral como ponto turístico, constantes no gráfico 1 a seguir. Acredita-se que essa resposta esteja vinculada à mídia e aos canais de comunicação por meio de propagandas televisivas, impressas ou mesmo propagandas turísticas, as quais expressam um valor à Catedral Nossa Senhora das Mercês por ser considerada pela mídia o cartão postal da cidade.

GRÁFICO 1 - RESULTADOS REFERENTES AO MÊS DE JULHO DE 2013

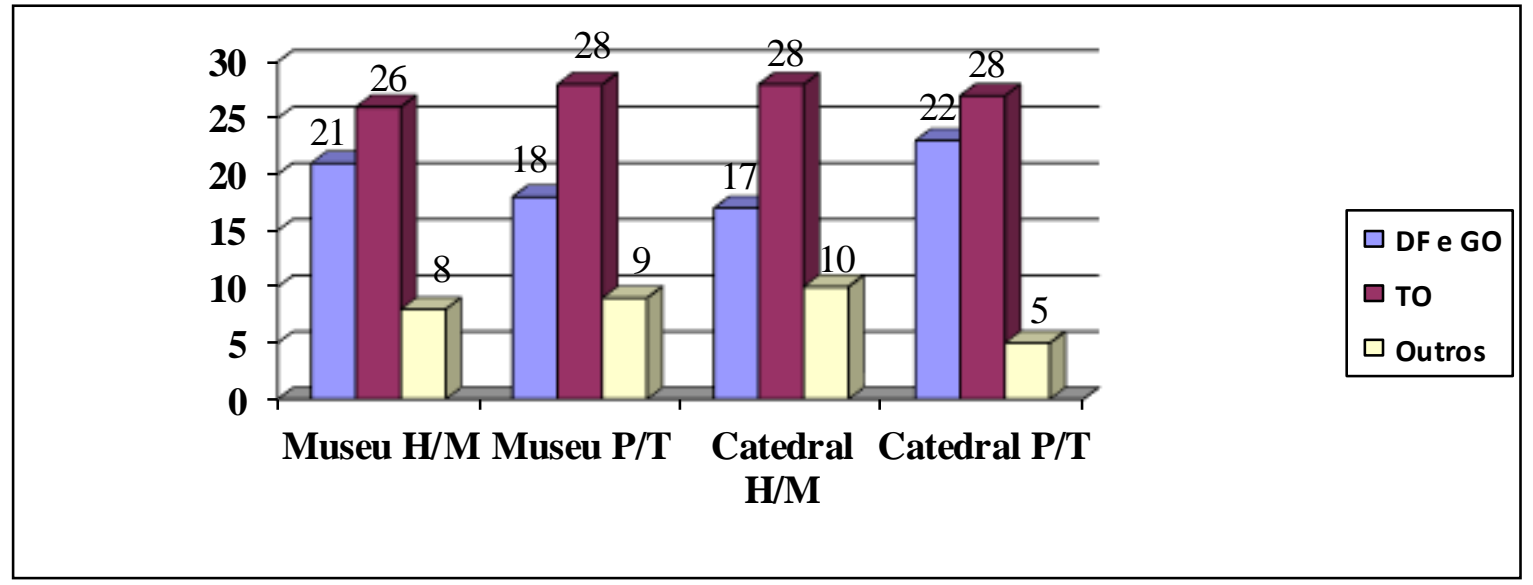

FONTE: Pesquisa de campo (2013).

*H/M - História e memória da cidade.

**P/T - Ponto turístico da cidade.

No período de dezembro, conforme disposto no gráfico 2, considerou-se ter havido uma contradição, pois, comparando ao gráfico anterior, o museu foi citado como ponto turístico para os turistas e/ou excursionistas do Distrito Federal e do estado de Goiás, com trinta e uma pessoas, e a Catedral obteve um número de vinte e quatro indicações. Acredita-se que esse resultado seja em função dos turistas, visitantes e/ou excursionistas, pois, nessa época, dezembro, final do ano, várias pessoas naturais de Porto Nacional retornavam no período de férias para celebrar as datas festivas, Natal e Ano Novo com a família. E, para os conterrâneos, os tocantinenses, a Catedral Nossa Senhora das Mercês ainda continuava sendo o símbolo que mais representava a cidade de Porto Nacional, por meio da história e da memória. 
GRÁFICO $2-$ RESULTADOS REFERENTES AO MÊS DE DEZEMBRO DE 2013

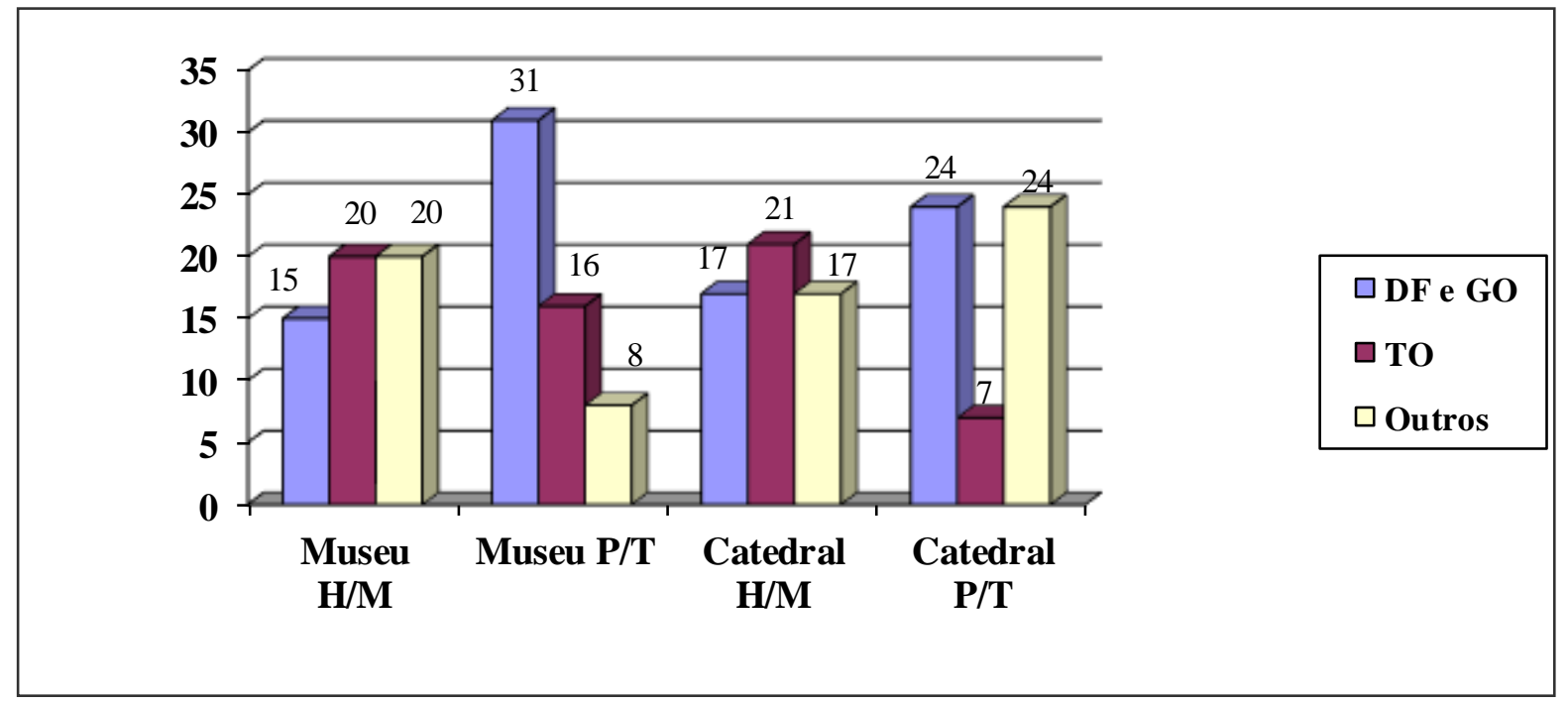

FONTE: Pesquisa de campo (2013).

*H/M - História e memória da cidade.

**P/T - Ponto turístico da cidade.

Considerou-se ser necessária fazer uma reflexão em complemento, uma visão além das respostas obtidas pelos questionários: a análise da opinião e da participação do morador do "polígono de tombamento", em caráter de estudo no processo de tombamento do Centro Histórico de Porto Nacional/TO. Para verificar o ponto de vista do turista e do morador, com objetivo de responder se a cidade de Porto Nacional representava o turismo cultural para os turistas e moradores após o tombamento.

Ao final das duas análises, chegou-se a um ponto de convergência ou divergência pertencente à opinião dos turistas e dos moradores: os pontos positivos e negativos no que tange ao processo de Tombamento do Centro Histórico de Porto Nacional.

\subsection{INTERPRETAÇÕES DOS MORADORES DO CENTRO HISTÓRICO}

As entrevistas foram realizadas no Centro Histórico, especificadamente na poligonal de tombamento, seguindo o mapa retificado, válido a partir de 2012 (ver FIGURA 1). Foram visitados cento e quatro imóveis, para cada imóvel, um entrevistado, de preferência o proprietário das residências. Já nas instituições entrevistadas, foi escolhido o funcionário que possuísse mais tempo de trabalho. Apenas setenta e dois moradores participaram da entrevista, os trinta e dois restantes não 
estavam na residência, não quiseram participar ou o imóvel estava fechado. As perguntas realizadas da entrevista podem ser visualizadas no apêndice 2, do artigo.

Dos setenta e dois moradores entrevistados, quarenta e cinco eram proprietários dos respectivos imóveis, e os outros moravam de aluguel ou cedido. Por comparação com o maior índice de proprietários, estes foram encontrados na Rua Coronel Pinheiro, conhecida também como Cabaçaco; Rua Padre Antônio e a Rua Francisco Aires da Silva. Essas três ruas do Centro Histórico eram as em que mais existiam proprietários do que residentes, conforme o quadro 1. Esse alto índice de moradores nessas ruas, em comparação com os demais, denotou mais evidência em termos de manifestações culturais que aconteciam nessas ruas citadas. Nelas, estavam situando-se os imóveis significativos e representativos para o centro histórico, como: a Catedral, o Museu, o Arquivo, a Casa de Cultura, a COMSAÚDE, localizados em umas das ruas citadas anteriormente. Das três ruas com o maior índice de proprietários, a rua Coronel Pinheiro se sobressaiu devido a ser uma das ruas mais expressivas de Porto Nacional. É a rua que permitia o acesso ao rio, fosse para lavar roupas, tomar banho ou mesmo pescar, tanto para os moradores quanto para os turistas. Nessa mesma rua, já foi realizado o carnaval da cidade e também uma feira de artesanato esporádica.

Quanto às ruas João Aires Joca, Josué Negre e Travessa da Colina, corresponderam a apenas dois proprietários residentes em cada rua mencionada. Essas três ruas por serem isoladas e com poucas casas, em sua grande maioria, são casas fechadas por abandono ou herança não resolvida. Por esse motivo, foram encontrados apenas dois proprietários em cada uma das ruas para responder a pesquisa. Na tabela a seguir, podem-se ver algumas especificações notadas no Centro Histórico.

QUADRO 1 - ESPECIFICAÇÃO - CENTRO HISTÓRICO

\begin{tabular}{|l|c|c|c|}
\hline \multicolumn{1}{|c|}{ RUA } & PROPRIETÁRIOS & $\begin{array}{c}\text { IMÓVEIS } \\
\text { VAZIOS }\end{array}$ & $\begin{array}{c}\text { IMÓVEIS } \AA \\
\text { VENDA }\end{array}$ \\
\hline Coronel Pinheiro & 13 & 1 & 2 \\
\hline Francisco Aires da Silva & 10 & 1 & - \\
\hline João Aires Joca & 2 & - & - \\
\hline Josué Negre & 2 & 1 & 1 \\
\hline Mizael Pereira & 3 & & - \\
\hline Padre Antônio & 11 & 2 & - \\
\hline Praça Duque & - & - & - \\
\hline Praça Nossa Senhora das Mercês & 4 & 2 & 4 \\
\hline Travessa da Colina & 2 & - & \\
\hline Total geral & 45 & 7 & \\
\hline
\end{tabular}

FONTE: Pesquisa de campo (2013). 
Conforme o quadro 1, dos proprietários moradores favoráveis ao tombamento, nove eram da Rua Coronel Pinheiro; quatro da Rua Padre Antônio e seis da Rua Francisco Aires da Silva. Do universo de setenta de dois moradores entrevistados, trinta e um foram a favor do tombamento e apenas dezoito foram contra, os demais não quiseram responder a pesquisa. Considera-se importante esclarecer que a maior parte dos entrevistados que votaram contra o tombamento, na verdade, não foi contra o ato em si. Eles não concordaram com a forma de como estava sendo tombado o centro histórico de Porto Nacional, devido à falta de cuidados nessa área delimitada, informações obtidas pelos moradores por fontes orais.

Um resultado que chamou bastante atenção foi a falta de informação dos moradores sobre o processo de tombamento, pois, dos setenta e dois entrevistados, apenas quinze moradores conheciam o processo de tombamento ou tinha ouvido falar. Enquanto cinquenta e sete moradores desconheciam o processo de tombamento composto por dois documentos, a Ata de Tombamento e o Dossiê ${ }^{5}$. Quando ficaram sabendo do tombamento, suas casas já estavam tombadas e não poderiam mais sofrer nenhum tipo de alteração, caso contrário, seriam sujeitos a punições. Em uma das falas dos entrevistados, se pode perceber a indignação:

\footnotetext{
Não sabia que a minha casa tinha sido tombada, fizeram o tombamento sem autorização da população, as políticas públicas municipais e federal deixam a casa cair para depois tomar as providências [...]. Não há participação dos órgãos quanto à preservação do imóvel [...]. Há muita burocracia, os materiais para restaurar as casas são caros, quem tem a casa reformada é porque usou os próprios recursos. A maioria das pessoas que mora aqui no centro histórico não tem condições para arcar uma reforma (ENTREVISTADO, INFORMAÇÃO VERBAL, 2013).
}

Pode-se confirmar, com os dizeres de Messias (2012, p. 52), que "é essencial explicar à população a respeito da importância histórica e cultural daquele bem tombado seja por meio de exposições, feiras culturais, meios de comunicação e ensinamento nas escolas". No gráfico 3 a seguir, tem-se como averiguar as respostas dos moradores baseando-se nas entrevistas. A representação a seguir mostra informações sobre o índice de pesquisa que houve no Centro Histórico em relação ao processo de tombamento. Pôde-se verificar se após o tombamento houve melhora por meio de políticas públicas, em especial no âmbito municipal e federal, e logo as respostas de quantos foram a favor

\footnotetext{
${ }^{5}$ Documentos disponibilizados nas referências.
} 
e contra o tombamento do Centro histórico. No gráfico 3 a seguir, podem ser vistas com mais detalhes as respostas dos moradores do centro histórico.

GRÁFICO 3 - RESPOSTAS ENTREVISTADOS

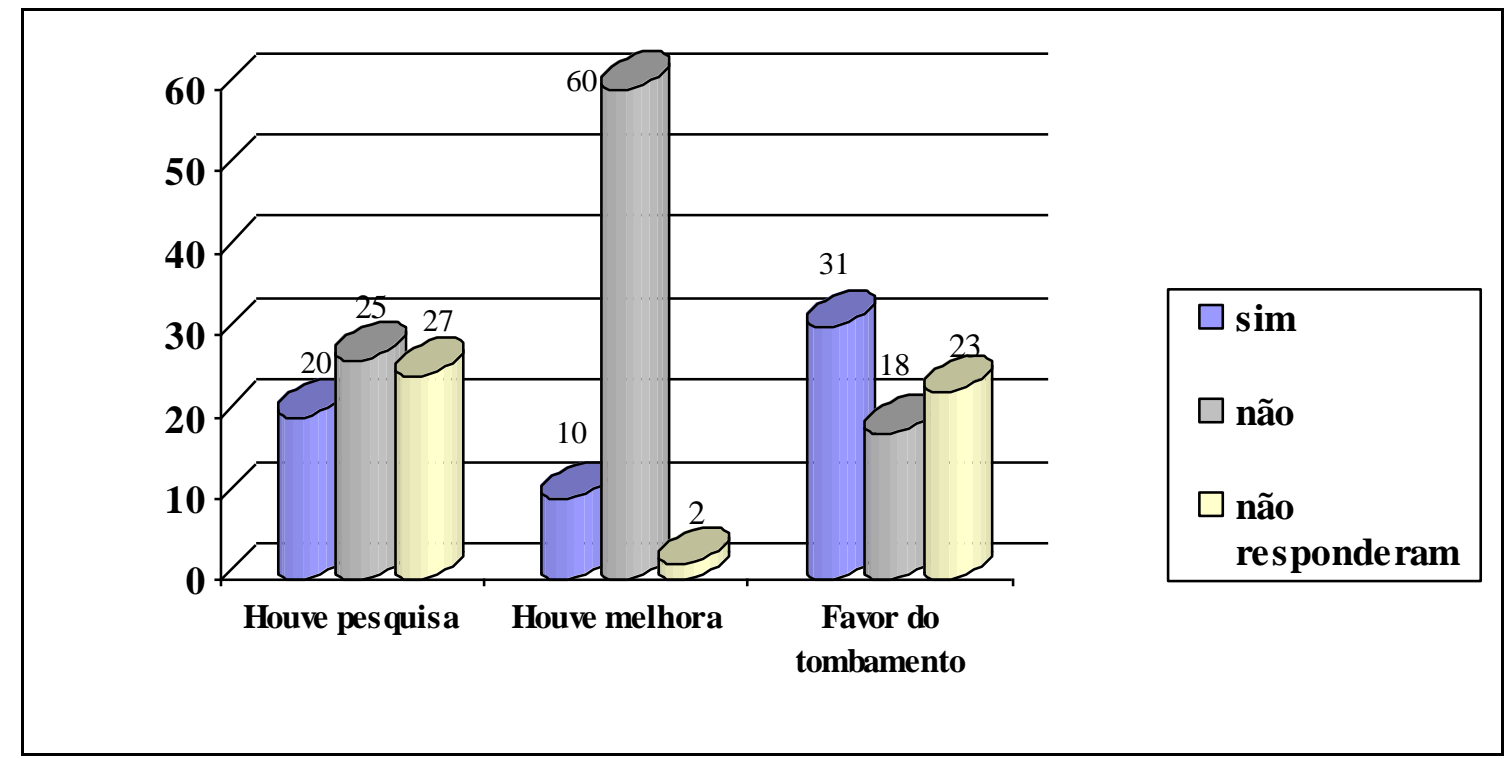

FONTE: Pesquisa de campo (2013).

Do universo de setenta e dois moradores entrevistados, vinte e três não quiseram informar sua posição, se foram contra ou a favor do tombamento. A maioria dessa parcela de entrevistados, pelas expressões gestuais e corporais, demonstrou restrição e certo receio em afirmar a sua opinião.

Já vinte e cinco dos moradores afirmaram que não houve nenhum tipo de comunicação, seja ela oralizada, via comunicação impressa, ou mesmo um plebiscito. Nesse sentido, o tombamento aconteceu devido aos interesses políticos, administrativos e econômicos, segundo as entrevistas orais obtidas dos moradores.

Para realizar o tombamento do centro histórico, segundo informações orais, houve três reuniões, mas essas reuniões eram informativas e não houve uma votação para saber quem queria que o centro histórico fosse tombado. Alguns moradores que participaram das reuniões afirmaram que:

Foi propaganda enganosa, disseram que quem morasse no centro histórico seria privilegiado, pois eles teriam um olhar especial, fizeram várias promessas, entre elas estavam a construção de um novo Coreto, a diminuição do IPTU, talvez a isenção, conservação e restauração das casas, promessas essas que só ficaram na reunião [...] (INFORMAÇÃO VERBAL, ENTREVISTADO, 2013). 
Vários foram os questionamentos negativos, nos dizeres de um dos moradores: “[...] meu IPTU vem um valor altíssimo [...]" e não deveria, pois como está no centro histórico, há uma redução no pagamento do imposto. Segundo o IPHAN (2009, p. 7), "[...] alguns municípios oferecem desconto de IPTU para bens tombados que forem mantidos em bom estado de conservação".

Considerou-se que as respostas a uma das perguntas contidas na entrevista destacaram-se: "Você conhece o processo de tombamento que resultou na preservação de uma área (polígono) no centro histórico?" Notou-se que a maioria dos moradores entrevistados desconhecia o processo de tombamento, esta resposta chamou a atenção, pois o centro histórico foi tombado no ano de 2008. E a pesquisa realizada em 2013, trouxe certa inquietação às pesquisadoras em saber que após cinco anos de tombamento a grande maioria dos moradores desconhecia essa informação.

$\mathrm{Na}$ entrevista com os moradores, foi perguntado se "houve melhoras no sentido de preservação, cuidados e/ou ações de prevenção para o centro histórico na paisagem por meio de políticas públicas, seja nos âmbitos federal, estadual e municipal?". O resultado de respostas a essa pergunta foi considerado como algo um tanto quanto surpreendente, pois na maioria das cidades históricas e tombadas existem incentivos ou mesmo ações de preservação e/ou restauração do patrimônio, o que não foi observado em Porto Nacional. Dos entrevistados sessenta pessoas afirmaram que desde 2008 não houve melhoras ou mesmo incentivos para restauração e/ou conservação do centro histórico e somente dez entrevistados afirmaram que houve melhora quanto à preservação do centro histórico por meio de políticas públicas nas esferas federal, estadual e municipal, e duas pessoas preferiram omitir a resposta.

Quanto ao turismo cultural em Porto Nacional, aproximadamente cinquenta dos moradores consideraram que havia o turismo cultural em Porto Nacional, respostas obtidas por meio da entrevista aplicada (ver apêndice B). Apesar de ser um número mínimo de pessoas que visitavam a cidade, mas ainda atraia muitas pessoas, tanto do estado do Tocantins quanto dos outros estados. Já doze moradores afirmaram que não havia turismo cultural em Porto Nacional, os citadinos afirmaram que "existia turismo quando tínhamos o rio Tocantins", outro entrevistado "somente na semana da cultura" (informação verbal dos entrevistados). 
Após as análises, o turismo cultural em Porto Nacional, para os turistas e/ou excursionistas, consistia nos monumentos existentes e fixados. Enquanto para os moradores eram os monumentos fixados como o coreto, os casarões em frente à Catedral e também o Rio Porto Real - Rio Tocantins. Mas ambos não mais existem em virtude da construção um extenso lago artificial. ${ }^{6} \mathrm{O}$ alagamento, entre outros danos, originou o desaparecimento das praias naturais do Rio Tocantins, mas houve a criação de algumas praias artificiais, enquanto medidas compensatórias (LIRA, 2010).

\section{CONSIDERAÇÕES FINAIS}

Após a realização do estudo, considerou-se poder afirmar que, na cidade de Porto Nacional, estava existindo a prática do turismo, mas com pouca intensidade, pois cinquenta dos moradores entrevistados, afirmaram existir a prática turística na cidade. Por meio dos resultados, considerou-se poder compreender que, apesar dos poucos atrativos turísticos que a cidade estava oferecendo, mesmo assim conseguiam atrair uma boa quantidade de turistas, principalmente no mês de julho e dezembro, em que o período de férias é nesses meses mais intensivo (GRÁFICOS 1 e 2). Quanto ao processo de tombamento, verificou-se haver rejeição por parte dos moradores devido à falta de iniciativas dos gestores públicos para a manutenção dos bens imóveis presentes no centro histórico. No momento da pesquisa, quanto ao estado das edificações, verificouse que a maioria dos imóveis estava carecendo de algumas reformas e restaurações emergenciais constantemente esquecidas de serem realizadas.

Neste estudo, pôde-se observar que a maioria dos turistas entrevistados considerou a Catedral Nossa Senhora das Mercês o símbolo que mais representava a História e a Cultura de Porto Nacional. Enquanto a Orla - Beira Rio obteve pouca preferência, ou seja, alguns turistas e/ou excursionistas não manifestaram acreditar que a Orla Beira Rio fosse considerada um símbolo cultural para a população portuense. $\mathrm{Na}$ ótica das presentes pesquisadoras, isso reflete no processo de intervenção antrópica para a construção da Orla - Beira Rio, por esse motivo não era tão enfática no sentido de representar a história da cidade. Assim, pode-se mencionar que essa característica de

\footnotetext{
${ }^{6}$ Com a implantação da Usina Luís Eduardo Magalhães (UHE), no ano de 2001, uma grande área foi alagada. $\mathrm{O}$ extenso reservatório se estende por aproximadamente $170 \mathrm{~km}^{2}$. (LIRA, 2010).
} 
intervenção foge ao que tange os conceitos que permeiam entre Patrimônio Cultural e Turismo Cultural, afirmando que a preservação, conservação e utilização desses bens culturais, em sua origem primária, permaneçam sem alterações na arquitetura. Isso no sentido de não modificar a paisagem, para que ela continue como forma de preservação da memória da cidade.

Pode-se concluir que o estudo apontou o Turismo Cultural como segmento turístico mais predominante na cidade de Porto Nacional, mediante a opinião dos moradores sobre processo de tombamento do Centro Histórico e dos moradores e turistas quanto à prática do turismo no seu centro histórico.

A pesquisa trouxe uma reflexão sobre a preservação do patrimônio histórico cultural, para pesquisas futuras, no sentido de preservar a memória da cidade. Ainda que o fluxo da atividade turística não seja tão intenso se comparado ao de outras cidades turísticas, mesmo assim, Porto Nacional ainda possui um potencial turístico.

\section{REFERÊNCIAS}

BRASIL. Ministério do Turismo. Segmentação do turismo: marcos conceituais. Brasília, DF: Ministério do Turismo, 2006.

Turismo cultural: orientações básicas. 3. ed. Brasília, DF: Ministério do Turismo, 2010. 96 p.

BARRETTO, M. História, educação e cidadania. Turismo em Análise, São Paulo, v. 3, n. 2, p. 34-43, nov. 1992. Disponível em:

<http://www.turismoemanalise.org.br/turismoemanalise/article/view/726/577>. Acesso em: 02/02/2016.

BENI, M. C. Análise estrutural do turismo. 8. ed. São Paulo: Ed. Senac, 2003.

CARVALHO, K. D. Turismo cultural e arqueologia nos espaços urbanos: caminhos para a preservação do patrimônio cultural. Turismo \& Sociedade, Curitiba, v. 3, n. 1, p. 51-67, abr. 2010. Disponível em:

<http://revistas.ufpr.br/turismo/article/view/17341/11405>. Acesso em: 15/05/2016.

COSTA, F. R. Turismo e patrimônio cultural: interpretação e qualificação. 2. ed. São Paulo: Ed. Senac, 2014. 251 p. 
BRASIL. Decreto-Lei n. 25, de 30 de novembro de 1937 c./c. o art. 15, parágrafo único, da Portaria n. 11, de 11 de setembro de 1986. dirige-se a todos os interessados para lhes NOTIFICAR que está promovendo por meio do Processo n. 01422.000186/2011-60, a rerratificação do tombamento do Centro Histórico de Porto Nacional. Diário Oficial [da República Federativa do Brasil], Brasília, DF, n. 199, 15 out. 2012. Seção 3, p.16.

GARCÍA CANCLINI, N. Consumidores e cidadãos: conflitos multiculturais da globalização. 3. ed. Rio de Janeiro: Ed. UFRJ, 1997. 266 p.

INSTITUTO DO PATRIMÔNIO HISTÓRICO E ARTÍSTICO NACIONAL (IPHAN). Ata da 59 $5^{\circ}$ Reunião do Conselho Consultivo do Patrimônio Cultural. Rio de Janeiro, 2008. Disponível em:

<http://portal.iphan.gov.br/portal/baixaFcdAnexo.do;jsessionid=A51F0D0C5DA2D747 2786109AB7CB0AA8FDE?id=2743>. Acesso em: 03/11/2013. (Ata do Tombamento do Município de Porto Nacional-TO).

Dossiê de tombamento do centro histórico de Porto Nacional - TO: Centro Histórico de Porto Nacional, notícia história. 2007.

Fiscalização. São Luís, MA: Iphan, 2009.

Portaria n. 486, de 29 de novembro de 2012. Aprova o Regimento Interno do Conselho Consultivo do Patrimônio Cultural. 2012. Disponível em:

< http://www.iphan.gov.br/baixaFcdAnexo.do?id=3249>. Acesso em: 15/11/2015.

LAKATOS, E. M; MARCONI, M. de A. Técnicas de pesquisa: planejamento e execução de pesquisas, amostragens e técnicas de pesquisa, elaboração análise e interpretação de dados. 4. ed. São Paulo: Atlas, 1999.

LIRA, E. O. A construção da UHE de Lajeado e os impactos sócioterritoriais no espaço urbano de Porto Nacional-TO. Palmas, TO: UFT, 2010. Dissertação (Mestrado em Desenvolvimento Regional e Agronegócio) - Universidade Federal do Tocantins, 2010.

MARUJO, N; SERRA, J; BORGES, M do R. Turismo cultural em cidades históricas: a cidade de Évora e as motivações do turista cultural. Turydes: revista de investigación em turismo y desarrollo local, España, v. 6, n. 14, p. 1-10, jun./jul. 2013. Disponível em: <http://www.eumed.net/rev/turydes/14/turismo-cultural.pdf >. Acesso em: $10 / 02 / 2016$.

MESSIAS, N. C. Porto Nacional: patrimônio cultural e memória. Goiânia: PUC Goiás, 2012.

MINAYO, M. C. S. O desafio da pesquisa social. In: MINAYO, M. C. S.; DESLANDES, S. F.; GOMES, R. (Org.). Pesquisa social: teoria, método e criatividade. 26. ed. Petrópolis: Vozes, 2007. p. 9-30.

MOLETTA, V. F. Turismo cultural. 3. ed. Porto Alegre: SEBRAE, 2001. 
NASCIMENTO, N. N. do N. Turismo cultural e a patrimonialização do polígono de tombamento do Centro Histórico de Porto Nacional - TO. 2014. 222 f. Dissertação (Mestrado em Geografia) - Universidade Federal do Tocantins, Porto Nacional, 2014.

OLIVEIRA, M. de F. Entre o sertão e o litoral: cultura e cotidiano em Porto Nacional 1880/1890. Anápolis: UEG, 2010.

Recebido em: 21-07-2016.

Aprovado em: 20-08-2016. 


\section{APÊNDICE A - QUESTIONÁRIO APLICADO AOS TURISTAS E/OU EXCURSIONISTAS}

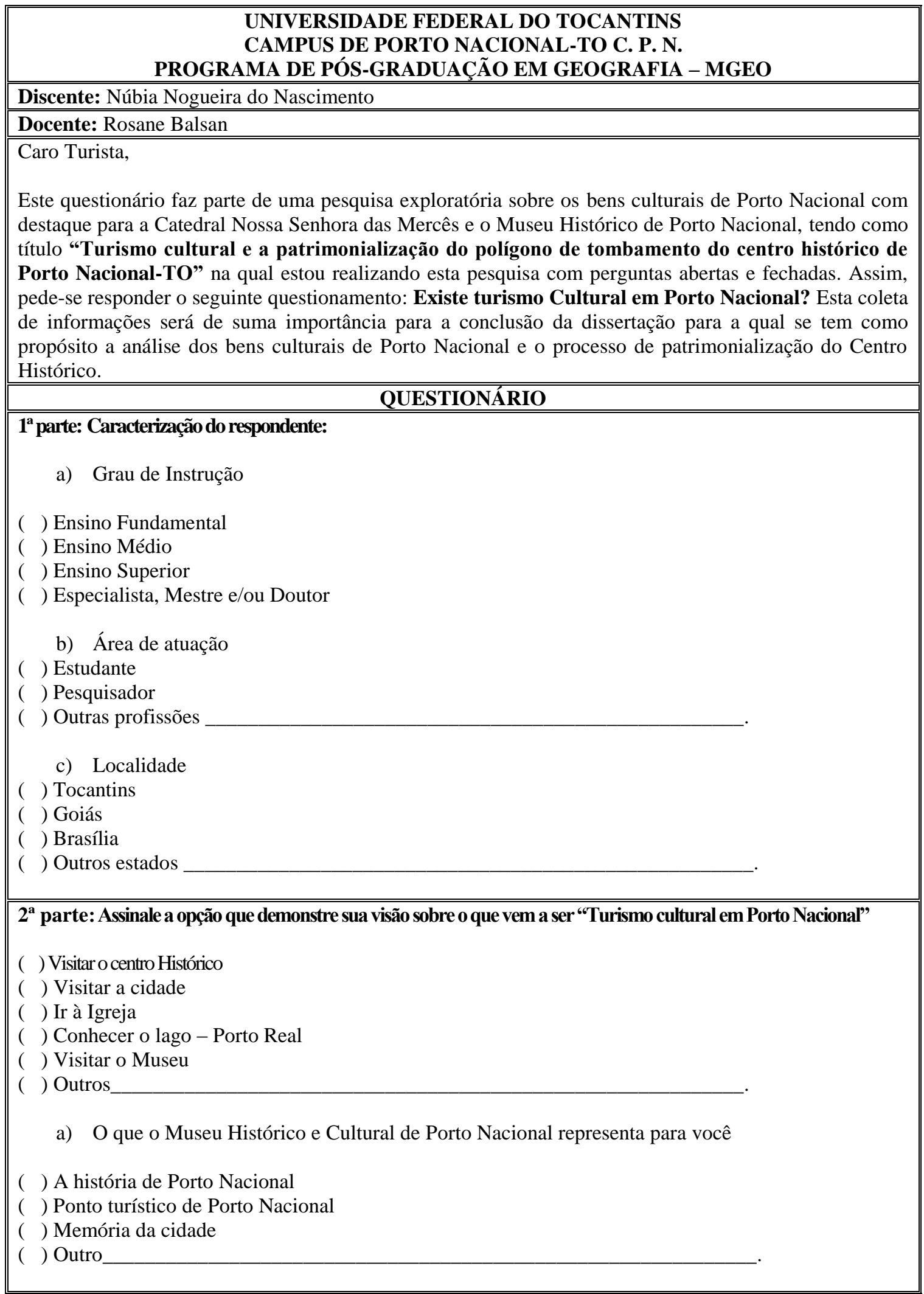

Continua... 
Continuação...

b) O que a Igreja Nossa Senhora das Mercês representa para você

( ) A história de Porto Nacional

( ) Ponto turístico de Porto Nacional

( ) Memória da cidade

( ) Outro

$3^{\text {a }}$ Em sua opinião qual destes símbolos representa Porto Nacional em termos de história e cultura?

( ) Museu Histórico e Cultural

( ) Colégio das Irmãs

( ) Catedral Nossa Senhora das Mercês

( ) Rio - Porto Real

( ) Orla

( ) Outro 


\section{APÊNDICE B - ENTREVISTA REALIZADA COM OS MORADORES DO CENTRO HISTÓRICO DE PORTO NACIONAL}

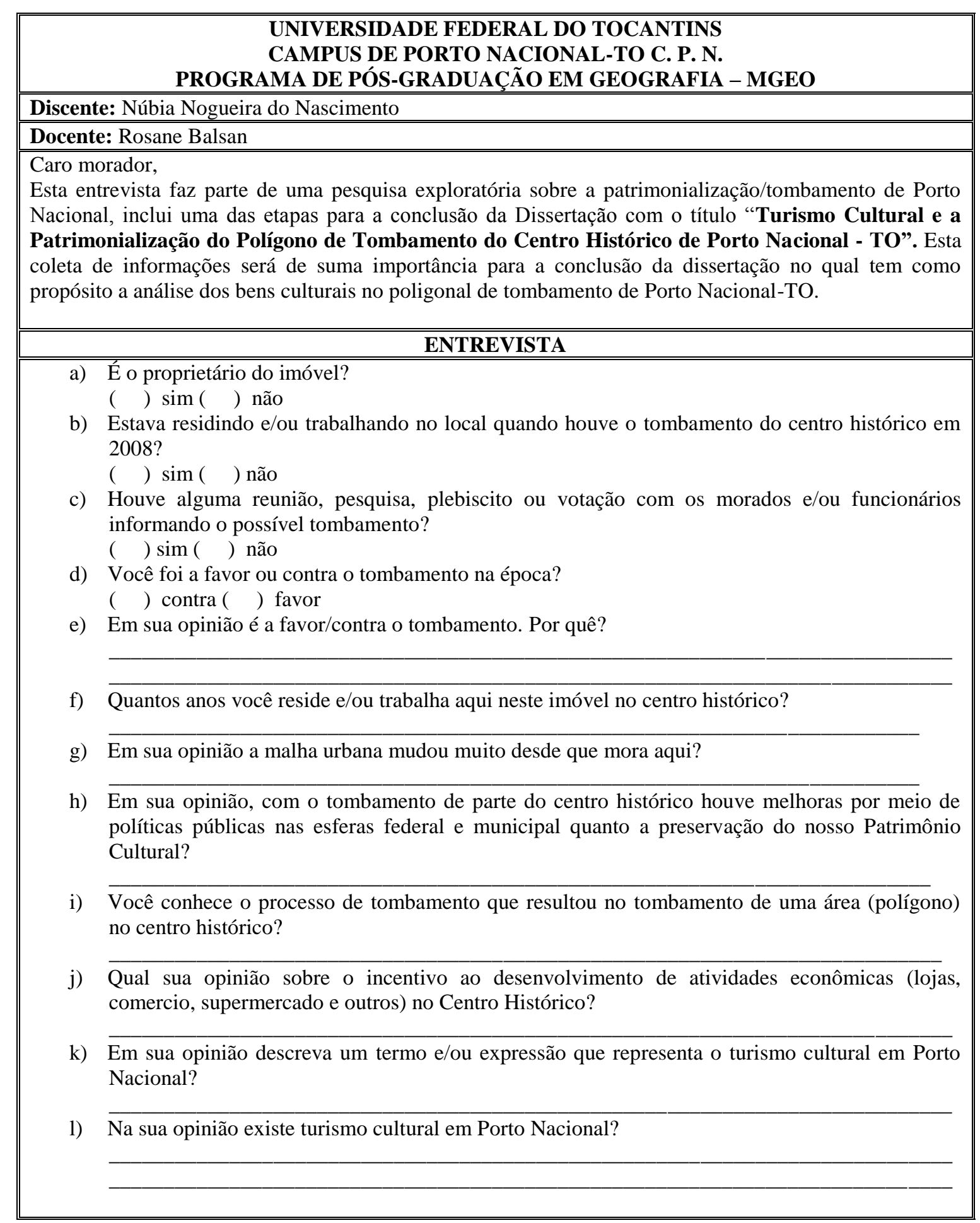

